\title{
IMPLEMENTASI KESELAMATAN LALU LINTAS UNTUK ANAK SEKOLAH DASAR YANG BERADA DI PINGGIR JALAN LINTAS BARAT
}

\author{
Alfian Saleh $*^{1}$, Fitridawati Soehardi ${ }^{2}$, Muthia Anggraini ${ }^{3}$ \\ Universitas Lancang Kuning; Jl.Yos Sudarso Km.8 Rumbai \\ Program Studi Teknik Sipil Fakultas Teknik Universitas Lancang Kuning \\ e-mail: alfian.saleh@unilak.ac.id
}

\begin{abstract}
Safety education is safety education to prevent, avoid or overcome the risk of injury and accidents. Safety education activities are part of public service conducted to students SDN 006 Sungai Pinang Kampar District, especially students of class I and students of class II. Community service is part of Tridharma Perguruan Tinggi. This activity aims to increase students' knowledge about safety in schools, especially regarding safety signs. Community service is a method of implementation of this community in the form of education followed by questions and answers and roleplay. The result of this activity is the students of SDN 006 Sungai Pinang Kampar Regency has been able to identify potential hazards and safety risks and to know the safety signs that can be applied in school, along with the meaning of each of these signs. The conclusion of this activity is the improvement of students' knowledge about safety signs in school. It is expected that with increased knowledge of safety signs, students' awareness to safer behavior increases.
\end{abstract}

Keywords - Clean and Healthy Lifestyle, Implementation, Slum Area

Abstrak
Pendidikan keselamatan adalah pendidikan tentang keselamatan untuk mencegah, menghindari atau mengatasi risiko cedera dan kecelakaan. Kegiatan pendidikan keselamatan merupakan bagian dari pelayanan masyarakat yang dilakukan kepada siswa SDN 006 Sungai Pinang Kabupaten Kampar, khususnya siswa kelas I dan siswa kelas II. Pelayanan masyarakat merupakan bagian dari Tridharma Perguruan Tinggi. Kegiatan ini bertujuan untuk meningkatkan pengetahuan siswa tentang keselamatan di sekolah, terutama mengenai tanda-tanda keselamatan. Pangabdian masyarakat adalah metode implementasi komunitas ini dalam bentuk pendidikan yang diikuti dengan pertanyaan dan jawaban dan roleplay. Hasil dari kegiatan ini adalah siswa SDN 006 Sungai Pinang Kabupaten Kampar telah mampu mengidentifikasi potensi bahaya dan risiko keselamatan dan untuk mengetahui tanda-tanda keselamatan yang bisa diterapkan di sekolah, beserta makna masing-masing tanda tersebut. Kesimpulan dari kegiatan ini adalah peningkatan pengetahuan siswa tentang tanda-tanda keselamatan di sekolah. Diharapkan dengan meningkatnya pengetahuan tentang tanda-tanda keselamatan, kesadaran siswa untuk berperilaku aman meningkat.

Kata Kunci- Pendidikan Keselamatan, Rambu-rambu Keselamatan, Resiko Keselamatan,

\section{PENDAHULUAN}

Banyak sekolah di kota besar yang berlokasi di tepi jalan raya, dimana banyak kendaraan yang melaju dengan kecepatan tinggi salah satunya jalan lintas barat. Jalan Lintas Barat menghubungkan Kota Pekanbaru dengan Kabupaten Kampar, bahkan beberapa jalan di Kota Pekanbaru disebut 'Lintasan Maut' seperti Jalan HR Soebrantas karena banyaknya truk yang melintas (Data Riau.com, 2014).

Kondisi seperti yang disebutkan di atas akan sangat membahayakan bagi siswa sekolah ketika akan menyeberang jalan. Siswa sekolah khususnya siswa SD (Sekolah Dasar) masih rentan 
terhadap kecelakaan dalam berlalu lintas seperti ketika menyeberang jalan. Menurut data lakalantas dari Polresta Kota Pekanbaru, Kabupaten Pelalawan dan Kabupaten Kampar tahun 2016 ini tidak terlalu signifikan dari tahun sebelumnya bahkan ada yang mengalami penurunan, namun resiko perlu kita antisipasi sebelum terjadi korban mengingat objek pengabdian ini adalah siswa SD yang notabene dihuni oleh anak-anak yang belum paham akan etika berlalu lintas khususnya pada saat jam masuk sekolah dan saat pulang sekolah. Dalam pendidikan dan kurikulum yang diajarkan disekolah tidak ada menyinggung mengenai tata cara berlalu lintas kepada siswa. Untuk itu pengetahuan ini perlu diberikan agar para siswa dapat mengetahui dan meningkatkan kesadaran akan berlalu lintas yang selamat.

\section{METODE}

Langkah awal yang dilakukan adalah menetapkan tempat dan waktu pelaksanaan serta mengirim undangan kepada mitra pengabdian. Tempat sosialisasi direncanakan di lokasi mitra yaitu Sekolah Dasar (SD) yang berada persis di pinggir jalan lintas barat yaitu SDN 006 Sungai Pinang kelas 1 dan kelas 2 . Waktu pelaksanaan sosialisasi dilaksanakan 1 hari dan pada waktu yang disesuaikan dengan waktu mitra yaitu waktu yang tidak menggangu jam belajar siswa.

Metode pelaksanaan kegiatan pengabdian kepada masyarakat yaitu kegiatan pengenalan rambu-rambu lalu lintas dan penerapan etika saat berada di jalan raya. Kegiatan ini dilakukan dengan tahapan sebagai berikut:

1. Ceramah

Yaitu memaparkan materi mengenai keselamatan di sekolah meliputi potensi bahaya dan resiko keselamatan yang ada di sekolah khususnya dalam menyeberang jalan karena sekolah berada di pinggir jalan lintas yang lalu lintasnya cukup padat.

2. Tanya Jawab

Tanya jawab yang berfungsi untuk mengevaluasi tingkat pemahaman siswa siswi mengenai rambu-rambu keselamatan di sekolah.

3. Role Play

Berupa demonstrasi yang berbentuk games, dilakukan oleh para siswa siswi dibantu oleh fasilitator tentang penerapan rambu-rambu keselamatan di sekolah.

\section{HASIL DAN PEMBAHASAN}

Pelaksanaan program pengabdian masyarakat ini berupa pendidikan keselamatan di SDN 006 Sungai Pinang diikuti oleh kurang lebih 50 orang siswa siswi dari kelas I dan II. Kegiatan diawali dengan salam, kemudian pengenalan mengenai potensi bahaya dan resiko keselamatan di sekolah. Tim pengabdian mengajak siswa siswi untuk mengidentifikasi potensi bahaya dan resiko keselamatan di sekolah. Hasil identifikasi tersebut adalah para siswa siswi dapat mengetahui berbagai potensi bahaya dan resiko yang ada, antara lain tangga penghubung ke lantai dua dapat beresiko jatuh, lantai licin yang dapat menyebabkan jatuh dan cidera dan yang paling penting terjadi kecelakaan lalu lintas karena sekolah ini persis berada di pinggir jalan lintas provinsi yang fasilitas rambu keselamatannya sangat minim.

Setelah menjelaskan mengenai potensi bahaya dan resiko keselamatan yang ada di sekolah, selanjutnya adalah menjelaskan kepada siswa siswi mengenai rambu-rambu keselamatan sebagai bagian dari upaya pengendalian resiko. Rambu-rambu yang dijelaskan berupa rambu keselamatan lalu lintas di sekitar sekolah dan rambu keselamatan di dalam lingkungan sekolah. Para siswa siswi tampak antusias mendengarkan pemaparan mengenai rambu-rambu keselamatan. Bentu antusias terlihat dari semangat para siswa siswi bertanya dan menjawab pertanyaan sekitar materi yang diberikan.

Kemudian terakhir tim pengabdian melakukan kegiatan demonstrasi penerapan rambu keselamatan. Demonstrasi berupa role play dimana tim pengabdian berperan sebagai narrator sedangkan para siswa siswi yang sukarela mengajukan diri sebagai sukarelawan berperan sebagai 
pemain peran dari cerita yang diberikan. Para siswa siswi lainnya yang berperan sebagai penonton juga ikut terlibat aktif selama berlangsungnya role play. Berdasarkan demonstrasi ini dapat disimpulkan bahwa siswa siswi sudah mengetahui rambu-rambu keselamatan yang dapat diterapkan dan juga mengerti akan arti dari rambu-rambu tersebut.

Berdasarkan paparan kegitan diatas banyak informasi yang diperoleh siswa siswi SDN 006 Sungai Pinang mengenai rambu-rambu keselamatan di sekolah mereka. Sekitar $30-40 \%$ siswa dapat mengidentifikasi potensi bahaya dan resiko yang ada di SDN 006 Sungai Pinang. 50-60\% siswa siswi mampu menjelaskan kembali tentang rambu-rambu lalu lintas, dan 50\% siswa siswi yang hadir saat pelaksanaan pengabdian ini mau melakukan role play mengenai keselamatn di sekolah.

Secara keseluruhan acara ini berlangsung dengan baik, sesuai dengan waktu yang ditentukan dan mendapatkan atensi yang cukup baik dari seluruh pihak sekolah. Adapun kendala yang ditemukan adalah dalam membuat tertib siswa siswi agar disiplin dalam duduk berbaris selama mengikuti kegiatan dan juga membuat siswa siswi tetap fokus selama berlangsungnya kegiatan. Fun learning yang diterapkan dapat membuat $75 \%$ siswa siswi benar-benar mengikuti jalnnya kegiatan dengan optimal.

Pemahaman anak akan keselamatan dirinya tidak terlepas dari keterbatasan kognitif yang dimilikinya. Anak usia sekolah sebenarnya sudah mampu membedakan arti dari konsep selamat dan tidak selamat, namun karena perkembangan kognitif mereka masih berada pada tahap praoperasioanl yang salah satunya bercirikan ketidakmampuan menggunakan sudut pandangnya sendiri (egosentrisme), maka dalam situasi praktis, anak-anak lebih mengandalkan interpretasi mereka sendiri tentang apa yang dianggap selamat dan tidak selamat (Maakip,dkk.,2000). Sebagai contoh, anak-anak pada usia ini mengira jika mereka bisa melihat pengendara kendaraan bermotor mendekati mereka yang sedang menyeberang jalan, maka pengendara tersebut juga bisa melihat mereka dengan jelas. Anak-anak ini tidak mempertimbangkan adanya kemungkinan pandangan pengendara kendaraan bermotor bisa terhalang oleh banyak hal, seperti tikungan tajam sebagai akibat dari ketidakakuratan penilaian ini, anak-anak yang usianya muda rentan mengalami kecelakaan di jalan raya, bahkan di jalan raya sekalipun. Notoatmodjo (2007) menjelaskan pendidikan mempengaruhi pengetahuan. Adapun faktor-faktor lain yang mempengaruhi pengetahuan seseorang antara lain adalah usia, pendidikan, pengalaman, media massa dan sosial budaya.

\section{KESIMPULAN}

Beberapa kesimpulan dari kegiatan pengabdian masyarakat ini adalah siswa siswi SDN 006 Sungai Pinang mampu mengidentifikasi potensi bahaya dan resiko keselamatan yang ada di lingkungan sekolah serta mampu mengetahui tentang arti dan fungsi dari masing-masing rambu keselamatan yang telah dijelaskan. Diharapkan ada kegiatan pendidikan keselamatan lanjutan yang sasarannya lebih luas meliputi seluruh siswa siswi dari semua kelas, para guru dan orang tua.

Pemahaman anak pada setiap aspek keselamatan diri mungkin saja dibentuk oleh lingkungan social disekitarnya, terutama orang tua dan sekolah. Orang tua perlu lebih berperan aktif dengan mengajarkan secara langsung kepad anak berbagai potensi bahaya berikut cara-cara mengatasinya.

\section{SARAN}

Dari semua data yang ada disarankan:

1. Perlu adanya kerjasama dengan stakeholder seperti Polantas dalam kegiatan ini guna mengetahui kondisi rill di lapangannya.

2. Memperluas cakupan peserta meliputi seluruh siswa siswi, guru dan orang tua agar dapat membimbing anaknya untuk selalu waspada. 


\section{DAFTAR PUSTAKA}

[1] Data Riau.com, 2014, Jalan HR Soebrantas, Lintasan Maut di Pekanbaru, Aviable from : http://datariau.com/read-13-829-2014-10-24-jalan-hr-soebrantas-lintasan-maut-dipekanbaru.html, Accesed : 2016, April 13

[2] Peraturan Menteri Perhubungan Republik Indonesia Nomor PM 13 Tahun 2014 tentang Rambu Lalu Lintas

[3] Peraturan Menteri Perhubungan Republik Indonesia Nomor PM 34 Tahun 2014 tentang Marka Jalan

[4] Maakip,L, Sulaiman, W.S.W., Ismail,R, \& Jaafar, W.A.W. (2000), Pengetahuan kanakkanak terhadap aspek-aspek keselamatan diri: Satu kajian awal Seminar Psikologi-Psima

[5] Notoatmodjo, S. (2007). Promosi Kesehatan \& Ilmu Perilaku. Jakarta: Rineka Cipta.

[6] Best Practices In Geographic Information Systems-Based Transportation Asset Management: Office of Planning Federal Highway Administartion U.S Department of Transportation, 2012, Americ

[7] Saleh, A., Soehardi, F. and Putri, L.P. (1997). "Tinjauan Kecepatan Kendaraan Pada wilayah Zoss Di Jalan Lintas Barat Provinsi Riau, ”Jurnal Rab Contruction Research, RACIC, pp 205216.

[8] Hinze, J., and Bren, K. (1997). "The Causes of Trenching Related Fatalities and Injuries," Proceedings of Construction Congress V: Managing Engineered Construction in Expanding Global Markets, ASCE, pp 389-398.

[9] Jamal ma'mur asmani. 2009. Manajemen Strategi Pendidikan Anak Usia Dini. Yogyakarta: DIVA press.

[10] King, R.W. and Hudson, R. (1985). "Construction Hazard and Safety Handbook: Safety." Butterworths, England.

[11] Sujiono, Yuliani Nurani.2009.Konsep Dasar Pendidikan Anak Usia Dini.Jakarta 